\title{
Fluid Resuscitation Guided by Stroke Volume Variation in Septic Shock
}

\author{
Roeya Mohamoud Aboelnasr ${ }^{1 *}$, Asmaa Fawzy Amer², Raghda Ghonimy Elsheikh³, \\ Ghada Fouad ELbaradey $^{2}$ and Sohair Mostafa Soliman ${ }^{2}$
}

${ }^{1}$ Department of Emergency Medicine and Traumatology, ${ }^{2}$ Department of Anesthesia and Surgical Intensive Care, ${ }^{3}$ Department of Cardiovascular Medicine, Tanta University Faculty of Medicine, Elgeish Street, Tanta, Gharbia Governorate, Egypt

*Corresponding author

\section{A B S T R A C T}

\section{Keywords}

Septic shock, Echocardiography, Early goal directed therapy, End points of resuscitation

Article Info

Accepted:

20 June 2019

Available Online:

10 July 2019
This study was done to evaluate fluid resuscitation guided by stroke volume variation in septic shock. This prospective randomized included sixty patients presented with hypotension (MAP less than $65 \mathrm{mmHg}$ ) and hyperlactatemia (serum lactate above 2 $\mathrm{mmol} / \mathrm{L}$ ) in intensive care unit (ICU). Patients were randomly classified into two groups, 30 patients for each group; group I (Early-goal-directed-therapy group \{EGDT\}) and group II (stroke volume variation guided fluid resuscitation). In group I mortality rate was $33.33 \%$ in comparison to $23.33 \%$ in group II with no statistically significant difference between two groups. As regard SOFA score, there was statistically significant decrease in 72 hours SOFA score in group II than in group I. Comparing fluid given between two groups showed highly significant increase in amount of fluid in group I than group II. Incorporation of echocardiography early in management of septic shock patients resulted in decrease in the amount of fluid and decrease useless administration of inotropes, early administration of inotropes after assessment of cardiac function by echocardiography which could help in improvement of septic shock outcomes and early vasopressor administration.

\section{Introduction}

Septic shock is a complex hemodynamic failure syndromes, as it implies derangement of all the three mainstays of cardiovascular homeostasis, each one to a variable degree: absolute or relative reduction in central blood volume, peripheral vasodilatation and myocardial failure may coexist and variably overlap in different phases of septic shock occurs.

Since 2002, the Surviving Sepsis Campaign (SSC) has promoted that protocolized delivery of 6 hours of early, goal-directed therapy (EGDT) to patients presenting to the emergency department with early septic shock reduced hospital mortality and hospital sta. 
Fluid responsiveness is defined by a cardiac preload challenge by fluid infusion resulting in augmented stroke volume (SV) and cardiac output (CO)

The use of ECHO as hemodynamic monitoring tool has already been validated in populations of septic shock patients(1), so as have been many of the most ECHO indices of volume responsiveness(2). In patients already monitored invasively, both transthoracic ECHO (3) and transesophageal ECHO add new relevant information that leads to changes in therapy in more than $50 \%$ of cases $(4,5)$ the majority of which concern volume status and inotropy.(6)

In this study, we aimed to evaluate the efficacy of fluid resuscitation guided by stroke volume variation in septic shock compared by early goal directed therapy as regard mortality

\section{Materials and Methods}

This study was carried out in Tanta University Emergency Hospital from April 2016 to April 2017 on 60 patients presented with hypotension (MAP less than $65 \mathrm{mmHg}$ ) and hyperlactatemia (serum lactate above 2 $\mathrm{mmol} / \mathrm{L})$ with suspected site of infection in intensive care unit (ICU). Adult patients aged $\geq 18$ years old who had infection and diagnosed as sepsis were included in the study when developed hypotension (MAP less than $65 \mathrm{mmHg}$ ) and hyperlactatemia (serum lactate above $2 \mathrm{mmol} / \mathrm{L}$ ). Patients aged $>65$ years old, pregnant women, survival $<24$ hours, patients presented with multiple organ failure, history of chronic cardiac disease were excluded from the study.

The study was approved by the Research Ethics Committee of Tanta university Faculty of Medicine

\section{Study setting and population and protocol}

Patients were randomly classified into two groups, using closed sealed envelopes. Assuming mortality rate of $33 \%$ in Earlygoal-directed therapy group(EGDT) group (Group I), the sample size was calculated at 60 of $80 \%$ power to detect a relative reduction of $11 \%$ in mortality rate in Stroke Volume Variation Group (SVV) group (Group II) (7, 8).

\section{In Group I (EGDT)}

All patients in this group underwent timely insertion of central venous catheter capable of continuous CVP (central venous pressure) and $\mathrm{ScVO} 2$ (central venous oxygen saturation) monitoring.

We measured lactate, mean arterial blood pressure (MAP), urinary output (UOP), central venous pressure (CVP), central venous oxygen saturation ( $\mathrm{ScVO} 2)$ at baseline and then after 1 hour, 3 hours and 6 hours respectively. The resuscitation followed the Surviving Sepsis Campaign (SSC) guidelines and included bundle of interventions within the first hour, 3 and 6 hours;

The targets of these bundles were to achieve the Early Goal Directed

Therapy (EGDT) protocol to obtain (9):

- CVP of 8-12 $\mathrm{cmH}_{2} \mathrm{O} ;$ Mechanical ventilation and increased abdominal pressure, require higher CVP targets of 12-15 $\mathrm{cmH}_{2} \mathrm{O}$.

Mean arterial pressure $\geq 65 \mathrm{mmHg}$;

Mixed venous oxygen saturation $\mathrm{ScVO} 2 \geq$ $70 \%$.

Urine output $\geq 0.5 \mathrm{ml} / \mathrm{kg} /$ minute. 


\section{In Group II (SVV)}

For this study group, we measured lactate, mean arterial blood pressure (MAP), urinary output (UOP), central venous pressure (CVP), central venous oxygen saturation $(\mathrm{ScVO} 2)$ at baseline and then after 1 hour, 3 hours and 6 hours respectively.

The patients were assessed at baseline by echocardiography measuring stroke volume variation(SVV), then the patient received $5 \mathrm{ml} / \mathrm{kg}$ crystalloid then reassessed again by Echocardiography; if the patient's MAP $<65$ $\mathrm{mmHg}$, another $5 \mathrm{ml} / \mathrm{kg}$ crystalloid were given till reaching the target of $65 \mathrm{mmHg}$, if CVP reached the target $(8-12 \quad \mathrm{cmH} 2 \mathrm{O}$ in spontaneously breathing patients or 12-15 $\mathrm{cmH} 2 \mathrm{O}$ in mechanically ventilated patients) and MAP still < $65 \mathrm{mmHg}$, vasopressor (noradrenaline $\quad(0.01-3 \quad \mathrm{mcg} / \mathrm{kg} / \mathrm{min}) \quad$ IV infusion) was applied to maintain MAP > $65 \mathrm{mmHg}$ and if there was LV dysfunction, inotropes [dobutamine infusion was added (maximum $20 \mu \mathrm{g} / \mathrm{kg} / \mathrm{min}$ )]

In this study group, therapy was adjusted according to the echocardiographic findings at time of admission and after giving $5 \mathrm{ml} / \mathrm{kg}$ IV fluids. ECHO guided fluid therapy by Stroke volume variation of more than $12 \%$, fluid boluses $(5 \mathrm{ml} / \mathrm{kg})$ were continued then reassessment was done SVV was less than 12 $\%$.

When septic myocardial dysfunthction was present, inotropes were started (dobutamine infusion was added (maximum $20 \mu \mathrm{g} / \mathrm{kg} / \mathrm{min})$ ).

When cardiac function was normalized, inotrope was continued at the same dose until the patient became hemodynamically stable. Inotropes were withdrawn in hyperdynamic cardiac function.
Transthoracic echocardiography was performed by using Philips Affiniti 50G at admission in ICU aiming to assess two specific parameters:

Stroke volume variation (SVV) is the change between the maximal and minimal stroke volumes divided by the average value over a period of time(10)

$\mathrm{SVV}=100 \mathrm{x}(\mathrm{SVmax}-\mathrm{SVmin}) / \mathrm{SV}$ mean

SV calculated by measuring VTI (velocity Time Integral) of aortic blood flow and diameter at the same point. This was performed by measuring the diameter of the LVOT (Left Ventricular Outflow Tract) in the parasternal long axis (PLAX) view, then switched to an apical five-chamber view, the pulse wave (PW) Doppler sample box was placed at the same point at which the LVOT was measured in the PLAX view.

The VTI was then traced. The product of VTI and aortic area equaled the stroke volume; considering that the aortic diameter was constant, multiplying the result by heart rate yielded cardiac output. Stroke volume variation of more than $12 \%$ accurately predicted that this patient was fluid responsive $(10,11)$.

\section{Outcome measures}

\section{Primary outcome}

The primary outcome was assessment of mortality rate.

\section{Secondary outcomes}

Secondary outcomes to be assessed were; need and duration of mechanical ventilation, length of ICU stay, sequential organ failure assessment score (SOFA) (12)at time of admission $(0 \mathrm{hr}), 36$ hours and after 72 hours. 


\section{Results and Discussion}

In this study, group I age of the studied patients ranged from 34 - 65 years with mean value of $58.83 \pm 6.53$ years, while group II age of the studied patients ranged from 26 65 years with mean value of $54.93 \pm 10.70$ years. In group I, male patients were 17 patients $(56.67 \%)$ whereas, in group II, male patients were 16 patients $(53.33 \%)$. As regard patient weight, in group I, the weight had a mean value of $80.500 \pm 7.807 \mathrm{~kg}$ while in group II, the weight mean value was $76.67 \pm$ $9.22 \mathrm{~kg}$.

There was significant increase in MAP at 3 hours in group II than in group I (p-value $<0.001$ ), whereas there were insignificant differences between MAP mean values at baseline, first hour, and at 6 hours (p-value $=0.504,0.146,0.204$ respectively). As regard UOP, there was insignificant differences between UOP mean values at baseline, 1hour, 3 hours and 6 hours $(p$-value $=0.836,1,0.590$, 0.194 respectively) (Table 1 ).

As regard CVP changes, there were significant increases in CVP mean values in group I compared to group II at 1 hour, 3 hours, and 6 hours (p-value $<0.001,<0.001$, 0.006 respectively) whereas, no significant difference was detected between CVP mean values at baseline (p-value $=0.661)$. In comparison between groups, there was insignificant difference between $\mathrm{ScVO} 2$ mean values at baseline 1 hours 3 hours and 6 hours $(\mathrm{p}$-value $=0.310, \quad 0.338, \quad 0.324, \quad 0.544$ respectively).

There was significant decrease in the mean values of SVV assessment after vasopressor compared to before vasopressor ( $p$ value $<0.001)$. Comparing the fluid given in both groups during resuscitation in 6 hours, there was highly significant increase in amount of fluid in group I than group II (p. value < 0.001) (Table 2).
Comparison between two studied groups, vasopressor timing was earlier in group II as compared to group I with statistically significant difference. ( $\mathrm{p}$-value $<0.001$ ). As regard vasopressor maximum dose, there was statistically significant increase in vasopressor maximum dose in group I than group II ( $p$ value $=0.038)$.

Ten patients died in group I with mortality rate $(33.33 \%)$ in comparison to 7 patients in group II with mortality rate (23.33\%). Mortality rate in group II was less than group I but statistically insignificant ( $\mathrm{p}$ value = 0.390).

Transthoracic echocardiography (TTE) is a promising technique for guiding hemodynamic management to improve outcomes in septic shock. Echocardiography is non-invasive and available in most intensive care units (ICUs) $(13,14)$. Both fluid responsiveness and cardiac dysfunction (common in patients with septic shock) can be quickly identified with TTE (15).

This prospective randomized study compare fluid resuscitation using stroke volume variation and ordinary early-goal directed therapy as end points of resuscitation in sixty patients presented with septic shock in intensive care unit (ICU)

In this study, as regard mortality as a primary outcome, mortality rate in group II was less than group I but statistically insignificant. The overall mortality rate was $28.33 \%$. In agreement with our study, Rowan et al., studied the early goal directed therapy resuscitation for septic shock in 3723 patients at 138 hospitals in seven countries, they demonstrated that mortality at 90 days as a primary outcome was similar for EGDT $24.9 \%$ and usual care was $25.4 \%$ (16).

Similar to our study, in a study by Lanspa et $a l$, they investigated echocardiogram-guided 
resuscitation versus early goal-directed therapy in the treatment of septic shock on 30 patients. They divided patients into two groups. Overall 28-day mortality rate as a secondary outcome was $26 \%$ with no statistically significant difference between two groups (8) (Table 3-5).

Table. 1 Changes in MAP, UOP, CVP, ScVO2 in group I \& group II at baseline, 1 hour, 3 hours $\& 6$ hours

\begin{tabular}{|c|c|c|c|c|}
\hline \multirow{5}{*}{ MAP } & & Group I & Group II & P value \\
\hline & $\begin{array}{l}\text { Base } \\
\text { line }\end{array}$ & $55.53+4.22$ & $54.83+3.82$ & 0.504 \\
\hline & 1 Hour & $59.63 \pm 3.76$ & 58.33 & 0.146 \\
\hline & 3 Hours & $65.07+7.35$ & $73.17+6.63$ & $<0.001$ \\
\hline & 6 Hours & $75 \pm 4.15$ & $73.17 \pm 6.63$ & 0.204 \\
\hline \multirow[t]{4}{*}{ UOP } & $\begin{array}{l}\text { Base } \\
\text { line }\end{array}$ & $38.33 \pm 11.77$ & $37.67 \pm 13.05$ & 0.836 \\
\hline & 1 Hour & $80.00 \pm 12.87$ & $80.00 \pm 12.87$ & 1.000 \\
\hline & 3 Hours & $167.83 \pm 153.82$ & $150.67 \pm 80.04$ & 0.590 \\
\hline & 6 Hours & 275.00116 .52 & $316.67 \pm 128.88$ & 0.194 \\
\hline \multirow[t]{4}{*}{ CVP } & $\begin{array}{l}\text { Base } \\
\text { line }\end{array}$ & $1.87 \pm 1.31$ & $2.00 \pm 1.02$ & 0.661 \\
\hline & 1 Hour & $8.50 \pm 1.82$ & $4.60 \pm 1.50$ & $<0.001 *$ \\
\hline & 3 Hours & $10.57 \pm 1.81$ & $8.07 \pm 2.80$ & $<0.001 *$ \\
\hline & 6 Hours & $12.00 \pm 1.26$ & $10.47 \pm 2.69$ & $0.006^{*}$ \\
\hline \multirow[t]{4}{*}{$\mathrm{ScVO}^{2}$} & $\begin{array}{l}\text { Base } \\
\text { line }\end{array}$ & $57.90 \pm 3.55$ & $58.90 \pm 4.00$ & 0.310 \\
\hline & 1 Hour & $60.13 \pm 3.35$ & $61.03 \pm 3.85$ & 0.338 \\
\hline & 3 Hours & $70.67 \pm 6.98$ & $71.87 \pm 6.43$ & 0.324 \\
\hline & 6 Hours & $76.47 \pm 3.61$ & $75.80 \pm 4.77$ & 0.544 \\
\hline
\end{tabular}

Table.2 Changes in SVV in group II after fluid resuscitation and after vasopressor

\begin{tabular}{|c|c|c|c|c|}
\hline $\begin{array}{c}\text { After fluid } \\
\text { resuscitation }\end{array}$ & $\begin{array}{c}\text { SVV \% } \\
(\mathbf{n = 3 0 )}\end{array}$ & $26.83 \pm 8.31$ & $10.63 \pm 1.01$ & $<0.001^{*}$ \\
\hline $\begin{array}{c}\text { After } \\
\text { vasopressors }\end{array}$ & $\begin{array}{c}\text { SVV \% } \\
(\mathbf{n = 3 0})\end{array}$ & $19.63 \pm 9.01$ & $12.69 \pm 1.86$ & $<0.001^{*}$ \\
\hline
\end{tabular}

Table.3 Fluid given in both groups (ml) during resuscitation

\begin{tabular}{|c|c|c|c|c|c|}
\hline $\begin{array}{c}\text { Fluid given } \\
(\mathbf{m l})\end{array}$ & \multicolumn{4}{|c|}{ Groups } & \multirow{2}{*}{ P-value } \\
\cline { 2 - 6 } & \multicolumn{2}{|c|}{ Group I } & \multicolumn{2}{c|}{ Group II } & \\
\hline Mean \pm SD & 2413.333 & \pm 220.866 & 1418.333 & \pm 360.910 & $<0.001^{*}$ \\
\hline
\end{tabular}


Table.4 Vasopressor timing \& maximum dose in both groups

\begin{tabular}{|l|c|c|c|}
\hline & $\begin{array}{c}\text { Group I } \\
\text { Mean } \pm \text { SD }\end{array}$ & $\begin{array}{c}\text { Group II } \\
\text { Mean } \pm \text { SD }\end{array}$ & P-value \\
\hline Vasopressor timing (hrs) & $\mathbf{5 . 3 0} \pm \mathbf{1 . 2 9 1}$ & $\mathbf{2 . 5 7} \pm \mathbf{1 . 5}$ & $<0.001^{*}$ \\
\hline $\begin{array}{l}\text { Vasopressor maximum } \\
\text { dose (meg/kg/min) }\end{array}$ & $\mathbf{2 . 3 5} \pm \mathbf{0 . 6 1}$ & $\mathbf{1 . 9 0} \pm \mathbf{0 . 8 1}$ & $\mathbf{0 . 0 1 8 *}$ \\
\hline
\end{tabular}

Table.5 Left ventricular systolic and diastolic function at baseline in group II

\begin{tabular}{|c|c|c|}
\hline & $\begin{array}{c}\text { LV systolic function Baseline } \\
\text { N(\%) }\end{array}$ & $\begin{array}{c}\text { LV diastolic function } \\
\text { BaselineN }(\%)\end{array}$ \\
\hline Normal & $\mathbf{1 8}(\mathbf{6 0})$ & $\mathbf{2 5}(\mathbf{8 3 . 3})$ \\
\hline Dysfunction & $\mathbf{1 2}(\mathbf{4 0})$ & $\mathbf{5}(\mathbf{1 6 . 7 )}$ \\
\hline
\end{tabular}

In Mouncey et al., study of early goal directed therapy resuscitation for septic shock, patients were randomly assigned to receive either EGDT (a 6-hour resuscitation protocol) or usual care. The primary clinical outcome was mortality at 90 days. overall mortality rate was $29.3 \%$ which is near our study results(17)

Fluid administration improves organ perfusion up to a point. However, excess IV fluid administration may be associated with increased organ dysfunction and mortality (18-20). In resource-limited settings, the association between higher volumes of fluid administration and increased mortality appears to be causal $(21,22)$.

As regard the amount of fluid given, in group I (EGDT), there was statistically highly significant increase in amount of fluid in group I compared to group II.

In group II, from the 30 patients, 7 patients $(23.33 \%)$ resuscitated after receiving $10 \mathrm{ml} / \mathrm{kg}, 12$ patients $(40 \%)$ resuscitated after receiving $15 \mathrm{ml} / \mathrm{kg}, 5$ patients $(16.67 \%)$ resuscitated after receiving $20 \mathrm{ml} / \mathrm{kg}, \quad 3$ patients $(10 \%)$ resuscitated after receiving $25 \mathrm{ml} / \mathrm{kg}$ and 3 patients (10\%) resuscitated after receiving $30 \mathrm{ml} / \mathrm{kg}$. Most of cases were resuscitated after receiving $15 \mathrm{ml} / \mathrm{kg}$.
Against the current study, Garg et al., in their study on thirty-six patients of septic shock requiring ventilatory support (invasive/noninvasive). Primary endpoints were mean arterial pressure (MAP) of $\geq 65$ $\mathrm{mmHg}$ and CVP > $12 \mathrm{mmHg}$ or IVC CI $<20 \%$ in Groups I and II, respectively. Patients were given a fluid bolus $500 \mathrm{ml}$ of crystalloid half- hourly. Patients were followed till achievement of end- points or maximum of $6 \mathrm{~h}$. Primary end- point was reached in 31 patients (15 in Group I and 16 in Group II). Fluid infusion, by either method, had increased CVP and decreased IVC CI with resultant negative correlation between them (23). There was no significant difference in the amount of fluid infused and time to reach end-point in two groups.

Balk et al., study was made to predict fluid responsiveness in sepsis by echocardiography by measuring cardiac output (CO) and its response to fluid bolus. It demonstrated a decreased responsiveness to initial small fluid bolus as an indicator of a higher severity of sepsis. It also suggested an inverse relationship between patients' fluid responsiveness as observed by change in velocity time integral (VTI) and severity of sepsis (24). 
As regard vasopressor timing in our study, vasopressor timing was earlier in group II as compared to group I with statistically significant difference. As regard vasopressor maximum dose, there was statistically significant increase in vasopressor maximum dose in group I as compared to group II

As regard inotropes, there was statistically insignificant difference between two groups. 2 patients in group I developed hypotension and improved after cessation of inotropes which proved that inotropes were harmful to those patients and were not indicated.

As regard left ventricular (LV) systolic function, in group II patients, 12 patients $(40 \%)$ had left ventricular systolic dysfunction (LV ejection fraction <55\%). From them; 10 patients improved (33.33\%) and 2 patients did not improve $(6.67 \%)$ in another Echo assessment after giving fluid and inotropes.

Afessa et al., study included patients with severe sepsis and septic shock treated in ICU and studied the compliance with each of the six EGDT elements within 6 hours of severe sepsis or septic shock onset and hospital mortality. In 355 patients with septic shock included in the study, inotrope use was $50 \%$ and vasopressor use was $89 \%$. The compliance with use of vasoactive drugs were independently associated with mortality, also there was no independent association between hospital mortality and inotrope use (25).

In the study of Parker et al., 10 of the 20 patients with septic shock exhibited global hypokinesia and ventricular dilation during the first 48 hours after admission(26). Contrary to common sense, the authors found significantly impaired LV systolic function in survivors compared with nonsurvivors.
Subsequent studies demonstrated similar reversible global hypokinesia by echocardiography. Vieillard-Baron and colleagues observed global hypokinesia in 26 of 67 patients. Moreover, LVEF was compromised in survivors during the first 24 hours (27). In another study performed over a period of 5 years, survivors showed evidence of septic myocardial dysfunction, as suggested by compromised LVEF and higher LVEDV (28).

LV sepsis-related myocardial dysfunction is nowadays a well-known entity and both global and regional systolic wall motion abnormalities can be found (29). Hypodynamic pattern (low cardiac index associated with reduced ejection fraction, $\mathrm{EF}$, below $40-45 \%$ ) is described in up to $60 \%$ of septic shock patients, its detection should prompt inotropes administration, even if central venous pressure values indicated by guidelines as target for ceasing volume loading have not been reached yet (further increase in preload on an acutely failing LV may not only fail to increase oxygen delivery but may also cause harm) (27).

In our study, as regard left ventricular diastolic function in group II patients, echocardiography assessment at baseline showed that 25 patients $83.33 \%$ had normal left ventricular diastolic function while 5 patients $16.67 \%$ had left ventricular diastolic dysfunction.

In Brown et al., prospective, observational study conducted in two intensive care units at a tertiary care hospital, 78 patients with severe sepsis or septic shock underwent TTE within $6 \mathrm{~h}$ of ICU admission, after 18 to $32 \mathrm{~h}$, and after resolution of shock. Left ventricular (LV) diastolic dysfunction was defined according to modified American Society of Echocardiography 2009 guidelines. Twentyseven patients $(36.5 \%)$ had diastolic 
dysfunction on initial echocardiogram, while 47 patients $(61.8 \%)$ had diastolic dysfunction on at least one echocardiogram. Total mortality was $16.5 \%$. The highest mortality $(37.5 \%)$ was observed among patients with grade I diastolic dysfunction(30).

In the current study we found that patients in both groups reached the targets of end points of resuscitation as regard MAP, UOP, CVP and $\mathrm{ScVO} 2$ at 6 hours of resuscitation with less amount of fluid given in group II. We observed that group II had less mortality rate, also more improvement in SOFA score and lactate level values at 72 hours. Lactate clearance at 6 hours was higher in group II as compared to group I. Vasopressor maximum dose was lower in group II and was given earlier than group I and inotropes were given to selected patients of myocardial dysfunction with no side effects.

The primary limitation of our study is the small sample size. Blinding was not feasible because of the nature of the interventions, which is another limitation of our study.

It is concluded that incorporation of echocardiography early in management of septic shock patients resulted in decrease in the amount of fluid and decrease useless administration of inotropes, early administration of inotropes after assessment of cardiac function by echocardiography which could help in improvement of septic shock outcomes and early vasopressor administration.

\section{References}

1. Vieillard-Baron A, Prin S, Chergui K, Dubourg O, Jardin F. Hemodynamic instability in sepsis: bedside assessment by Doppler echocardiography. American journal of respiratory and critical care medicine. 2003; 168 (11): 1270-6.
2. Charron C, Caille V, Jardin F, VieillardBaron A. Echocardiographic measurement of fluid responsiveness. Current opinion in critical care. 2006; 12 (3): 249-54.

3. Splanchnic hypoperfusion-directed therapies in trauma: a prospective, randomized trial. The American surgeon. 2005; 71 (3): 252-60.

4. Manasia AR, Nagaraj HM, Kodali RB, Croft LB, Oropello JM, Kohli-Seth R, et al., Feasibility and potential clinical utility of goal-directed transthoracic echocardiography performed by noncardiologist intensivists using a small hand-carried device (SonoHeart) in critically ill patients. Journal of cardiothoracic and vascular anesthesia. 2005; 19 (2): 155-9.

5. Huttemann E, Schelenz C, Kara F, Chatzinikolaou K, Reinhart K. The use and safety of transoesophageal echocardiography in the general ICU -a minireview. Acta anaesthesiologica Scandinavica. 2004; 48 (7):827-36.

6. Members ATF, Steg PG, James SK, Atar D, Badano LP, Lundqvist CB, et $a l$., ESC Guidelines for the management of acute myocardial infarction in patients presenting with ST-segment elevation: The Task Force on the management of ST-segment elevation acute myocardial infarction of the European Society of Cardiology (ESC). European heart journal. 2012; 33 (20): 2569-619.

7. Harvey SE, Elbourne D, Ashcroft J, Jones CM, Rowan K. Informed consent in clinical trials in critical care: experience from the PAC-Man Study. Intensive care medicine. 2006; 32 (12): 2020-5.

8. Lanspa MJ, Burk RE, Wilson EL, Hirshberg EL, Grissom CK, Brown SM. Echocardiogram-guided resuscitation versus early goal-directed therapy in the 
treatment of septic shock: a randomized, controlled, feasibility trial. Journal of Intensive Care. 2018; 6( 1): 50.

9. Rhodes A, Evans LE, Alhazzani W, Levy MM, Antonelli M, Ferrer R, et al., Surviving Sepsis Campaign: International Guidelines for Management of Sepsis and Septic Shock: 2016. Intensive care medicine. 2017; 43 (3): 304-77.

10. Marik PE, Cavallazzi R, Vasu T, Hirani A. Dynamic changes in arterial waveform derived variables and fluid responsiveness in mechanically ventilated patients: a systematic review of the literature. Critical care medicine. 2009; 37 (9): 2642-7.

11. Feissel M, Michard F, Mangin I, Ruyer O, Faller JP, Teboul JL. Respiratory changes in aortic blood velocity as an indicator of fluid responsiveness in ventilated patients with septic shock. Chest. 2001; 119 (3): 867-73.

12. Vincent JL, Moreno R, Takala J, Willatts S, De Mendonca A, Bruining H, et al., The SOFA (Sepsis-related Organ Failure Assessment) score to describe organ dysfunction/failure. On behalf of the Working Group on Sepsis-Related Problems of the European Society of Intensive Care Medicine. Intensive care medicine. 1996; 22 (7): 707-10.

13. Barbier C, Loubieres Y, Schmit C, Hayon J, Ricome JL, Jardin F, et al., Respiratory changes in inferior vena cava diameter are helpful in predicting fluid responsiveness in ventilated septic patients. Intensive care medicine. 2004; 30 (9): 1740-6.

14. Feissel M, Michard F, Faller JP, Teboul JL. The respiratory variation in inferior vena cava diameter as a guide to fluid therapy. Intensive care medicine. 2004;30 (9): 1834-7.

15. Vieillard-Baron
cardiomyopathy. Annals of intensive care. 2011; 1(1): 6.

16. Rowan KM, Angus DC, Bailey M, Barnato AE, Bellomo R, Canter RR, et al., Early, Goal-Directed Therapy for Septic Shock - A Patient-Level MetaAnalysis. The New England journal of medicine. 2017; 376 (23): 2223-34.

17. Mouncey PR, Osborn TM, Power GS, Harrison DA, Sadique MZ, Grieve RD, et al., Trial of early, goal-directed resuscitation for septic shock. The New England journal of medicine. 2015;372(14):1301-11.

18. Boyd JH, Forbes J, Nakada TA, Walley KR, Russell JA. Fluid resuscitation in septic shock: a positive fluid balance and elevated central venous pressure are associated with increased mortality. Critical care medicine. 2011; 39 (2): 259-65.

19. Sadaka F, Juarez $M$, Naydenov $S$, O'Brien J. Fluid resuscitation in septic shock: the effect of increasing fluid balance on mortality. Journal of intensive care medicine. 2014; 29 (4):2 13-7.

20. Sakr Y, Rubatto Birri PN, Kotfis K, Nanchal R, Shah B, Kluge S, et al., Higher Fluid Balance Increases the Risk of Death From Sepsis: Results From a Large International Audit. Critical care medicine. 2017; 45(3): 386-94.

21. Andrews B, Semler MW, Muchemwa L, Kelly P, Lakhi S, Heimburger DC, et al., Effect of an Early Resuscitation Protocol on In-hospital Mortality Among Adults With Sepsis and Hypotension: A Randomized Clinical Trial. Jama. 2017; 318(13): 1233-40.

22. Maitland K, Kiguli S, Opoka RO, Engoru C, Olupot-Olupot P, Akech SO, et al., Mortality after fluid bolus in African children with severe infection. The New England journal of medicine. 2011; 364 (26): 2483-95.

23. Garg M, Sen J, Goyal S, Chaudhry D. 
Comparative evaluation of central venous pressure and sonographic inferior vena cava variability in assessing fluid responsiveness in septic shock. Indian journal of critical care medicine: peer-reviewed, official publication of Indian Society of Critical Care Medicine. 2016; 20(12):708-13.

24. Balk AH, Mihailos A, Yellin S, Melniker L, Chiricolo G. Predicting Fluid Responsiveness in Sepsis by Echocardiographic Evaluation. Annals of Emergency Medicine. 2013; 62 (4): S79.

25. Afessa B, Mullon JJ, Cartin-Ceba R, Schramm GE, Gajic O. Compliance with vasopressor use of early goal-directed therapy is not associated with decreased mortality in severe sepsis/septic shock. Critical Care. 2008; 12 (Suppl 5): P5-P.

26. Parker MM, Shelhamer JH, Bacharach SL, Green MV, Natanson C, Frederick TM, et al., Profound but reversible myocardial depression in patients with septic shock. Annals of internal medicine. 1984; 100 (4): 483-90.

27. Vieillard-Baron A, Caille V, Charron C, Belliard G, Page B, Jardin F. Actual incidence of global left ventricular hypokinesia in adult septic shock. Critical care medicine. 2008;36 (6):1701-6.

28. Jardin F, Fourme T, Page B, Loubieres Y, Vieillard-Baron A, Beauchet A, et al., Persistent preload defect in severe sepsis despite fluid loading: A longitudinal echocardiographic study in patients with septic shock. Chest. 1999; 116 (5):1354-9.

29. Rabuel C, Mebazaa A. Septic shock: a heart story since the 1960s. Intensive care medicine. 2006; 32 (6):799-807.

30. Brown SM, Pittman JE, Hirshberg EL, Jones JP, Lanspa MJ, Kuttler KG, et al., Diastolic dysfunction and mortality in early severe sepsis and septic shock: a prospective, observational echocardiography study. Critical ultrasound journal. 2012; 4(1): 8-.

\section{How to cite this article:}

Roeya Mohamoud Aboelnasr, Asmaa Fawzy Amer, Raghda Ghonimy Elsheikh, Ghada Fouad ELbaradey and Sohair Mostafa Soliman. 2019. Fluid Resuscitation Guided by Stroke Volume Variation in Septic Shock. Int.J.Curr.Microbiol.App.Sci. 8(07): 2783-2792.

doi: https://doi.org/10.20546/ijcmas.2019.807.340 